THEORY AND METHODS

\title{
Linking environmental effects to health impacts: a computer modelling approach for air pollution
}

\author{
Jennifer Mindell, Roger Barrowcliffe
}

J Epidemiol Community Health 2005;59:1092-1098. doi: 10.1136/jech.2005.036897

See end of article for authors' affiliations

Correspondence to:

Dr J Mindell, Department of Epidemiology and Public Health, University College London, 1-19 Torrington Place, London WCIE 6BT, UK; j.mindell@ ucl.ac.uk

Accepted for publication 1 August 2005
Study objective and Setting: To develop a computer model, using a geographical information system (GIS), to quantify potential health effects of air pollution from a new energy from waste facility on the surrounding urban population.

Design: Health impacts were included where evidence of causality is sufficiently convincing. The evidence for no threshold means that annual average increases in concentration can be used to model changes in outcome. The study combined the "contours" of additional pollutant concentrations for the new source generated by a dispersion model with a population database within a GIS, which is set up to calculate the product of the concentration increase with numbers of people exposed within each enumeration district exposure response coefficients, and the background rates of mortality and hospital admissions for several causes.

Main results: The magnitude of health effects might result from the increased $\mathrm{PM}_{10}$ exposure is smallabout 0.03 deaths each year in a population of 3500000 , with 0.04 extra hospital admissions for respiratory disease. Long term exposure might bring forward 1.8-7.8 deaths in 30 years.

Conclusions: This computer model is a feasible approach to estimating impacts on human health from environmental effects but sensitivity analyses are recommended.

Relevance to clinical or professional practice: The availability of GIS and dispersion models on personal computers enables quantification of health effects resulting from the additional air pollution new industrial development might cause. This approach could also be used in environmental impact assessment. Care must be taken in presenting results to emphasise methodological limitations and uncertainties in the numbers.
$\mathrm{E}$ nvironmental impact assessment is a legal requirement in the European Union, as in many parts of the world, for a range of structural and industrial projects. Consideration of impacts on human health is required ${ }^{1-4}$ but is seldom done..$^{5-7}$ Even when considered, health effects are seldom quantified. ${ }^{8}$

Many epidemiological studies show remarkably consistent associations between several health outcomes and exposure to increased concentrations of certain airborne pollutants, such as particulate matter $\left(\mathrm{PM}_{10}\right.$, particles of aerodynamic diameter less than 10 microns). ${ }^{9-12}$ The availability of geographical information systems (GIS) and dispersion models on personal computers makes applying this knowledge a realistic possibility for quantifying health effects of the additional air pollution from a new industrial development. Although spreadsheets and other models have been produced to quantify health effects of specific scenarios, ${ }^{13}{ }^{14}$ these have not been widely applied linked to GIS. By using a GIS, we are able to perform a large number of calculations for variables that display a large spatial variation. Without this tool, the task of aggregating the effects across such a wide area at this level of detail would be impossible.

In this case study, we have quantified some of the health effects of a new energy from waste facility on the surrounding population, in the context of environmental assessment for planning and licensing of the proposal.

\section{METHOD}

Our method was a development based on an existing computer spreadsheet model. ${ }^{13}{ }^{15}$ That model was based on changes in ambient pollution at monitoring sites resulting from policies to improve air quality in a local authority, assuming that levels changed in parallel across the whole area. This new method links the spreadsheet to a GIS, so that the health impact calculations for the modelled additional exposure experienced by the resident population of each enumeration district can be made. (The enumeration district (ED), containing around 100 residents, was the smallest output level in the UK's 1991 census. It has been superseded by output areas from the 2001 census.)

The quantification relies on the simple equation:

$\Delta \mathrm{E}=\beta \times \Delta \mathrm{C} \times \mathrm{P} \times \mathrm{E}$,

$(\Delta) \mathrm{E}=$ (change in) background rate of events;

$\beta=$ exposure-response coefficient;

$\Delta \mathrm{C}=$ change in concentration of pollutant;

$\mathrm{P}=$ population exposed.

The coefficients are derived from epidemiological studies, which show a clear association between increased exposure and increased effects. We have included only those pollutionhealth outcomes associations for which the evidence of a causal relation is at least moderately strong, based on systematic literature reviews ${ }^{13}$ (table 1 ).

When assessing potential health impacts of exposure to raised levels of criterion air pollutants from the proposed plant, we examined $\mathrm{PM}_{10}$, sulphur dioxide, and nitrogen dioxide. As this paper aims to describe the quantification method of a computer model combining geographical information with calculations, we have restricted description of the methods and findings to $\mathrm{PM}_{10}$ as an exemplar.

There is strong evidence that exposure to $\mathrm{PM}_{10}$ brings forward non-traumatic deaths ${ }^{913}$ and moderate evidence ${ }^{13}$ that $\mathrm{PM}_{10}$ increases emergency hospital admissions for circulatory $^{17}$ and respiratory ${ }^{17}$ diseases and accident and

Abbreviations: $G I S$, geographical information system; $E D$, enumeration district 
Table 1 Strength of evidence for causal relations for acute exposure to ambient levels

\begin{tabular}{|c|c|c|c|}
\hline \multicolumn{2}{|l|}{ Mortality } & \multicolumn{2}{|l|}{ Morbidity } \\
\hline Strong evidence & Moderate evidence & Strong evidence & Moderate evidence \\
\hline All non-traumatic deaths ${ }^{9}$ & $\begin{array}{l}\text { All respiratory disease }{ }^{16} \\
\text { Chronic obstructive pulmonary } \\
\text { disease plus asthma in people } \\
\text { aged } \geqslant 65^{16}\end{array}$ & & $\begin{array}{l}\text { Emergency hospital admissions for all } \\
\text { circulatory }{ }^{17} \text { and all respiratory diseases }{ }^{17} 18 \\
\text { and ischaemic heart disease }{ }^{17} \text { at all ages } \\
\text { Emergency hospital admissions in people aged } \\
\geqslant 65 \text { for chronic obstructive pulmonary disease } \\
\text { plus asthma }{ }^{17} 18 \text { and for pneumonia } 7 \\
\text { Asthma admissions in children and younger } \\
\text { adults }{ }^{17} \\
\text { Accident and emergency attendances for } \\
\text { asthma in children and younger adults }{ }^{19}\end{array}$ \\
\hline
\end{tabular}

emergency attendances for asthma. ${ }^{19}$ There is also moderate evidence that long term exposure to particulate matter increases deaths. ${ }^{1320}$ Within the range of ambient pollution encountered in the region, the health effects of particulate matter is linear and there is no good evidence of a threshold below which they have no effect on any person. ${ }^{15} 2122$ This assumption of no threshold is made based on the epidemiological evidence but results in being able to use the modelled increase in annual average concentration rather than all the individual 24 hour average concentrations that make up a year.

The anticipated emissions from the proposed incinerator were entered into the ADMS air pollution dispersion model $^{23}{ }^{24}$ to obtain "contours" of additional concentrations for the new source. This output file was easily transferred into the GIS. A population database at ED level for a $20 \mathrm{~km}$ radius by age group $(0-14,15-64,65+)$ was added to the GIS as another data layer.

The pollutant concentrations are represented by the dispersion model as lines. These were used to create small area polygons in the GIS, each defining an area with a single value for concentration. The polygons were formed by reference to the ED boundaries, so that each polygon had one total population value, with the assumption that the population was uniform across the whole area. Using an overlay function in GIS, the population data were combined with the $\mathrm{PM}_{10}$ concentration data, resulting in a single layer containing details of ED name, spatial area, population, and a $\mathrm{PM}_{10}$ concentration for many hundreds of non-uniform areas.

Table 2 Estimates used of percentage change in mortality and hospital admissions for the effect of an acute change of $1 \mu \mathrm{g} /$ $\mathrm{m}^{3} \mathrm{PM}_{10}$

\begin{tabular}{|c|c|c|c|c|c|c|c|}
\hline \multirow[b]{2}{*}{ Diagnostic category } & \multirow{2}{*}{$\begin{array}{l}\text { ICD-9 } \\
\text { codes }^{25}\end{array}$} & \multirow{2}{*}{$\begin{array}{l}\text { ICD-10 } \\
\text { codes }^{26}\end{array}$} & \multirow{2}{*}{$\begin{array}{l}\text { Age } \\
\text { group }\end{array}$} & \multirow{2}{*}{$\begin{array}{l}\text { Mean annual } \\
\text { number of } \\
\text { events } \\
20 \mathrm{~km} \text { area }\end{array}$} & \multicolumn{3}{|l|}{ Effect estimates } \\
\hline & & & & & London & APHEA-2 & Meta-analyses \\
\hline $\begin{array}{l}\text { All non-traumatic } \\
\text { deaths }\end{array}$ & $<800$ & $A^{*}-R^{*}$ & All & 29983 & $0.03 \%(-0.02 \text { to }+0.07)^{16}$ & $\begin{array}{l}0.06 \%(0.04-0.08) \\
(\operatorname{lag} 0-1)^{27} \\
0.16 \%(0.043-0.097) \\
\text { (distributed lag 0-40) }^{11}\end{array}$ & $\begin{array}{l}0.074 \%(0.062-0.086)(\mathrm{WHO}, \\
1997 \text { estimate })^{28} 29 \\
0.064 \%(0.048-0.077)^{30} \\
0.05(0.04-0.06)\left(\text { combined }^{29}\right. \\
\left.\text { APHEA and NMMAPS }{ }^{31}\right)\end{array}$ \\
\hline $\begin{array}{l}\text { All respiratory deaths } \\
\text { COPD + asthma } \\
\text { deaths }\end{array}$ & $\begin{array}{l}460-519 \\
490-496\end{array}$ & $\begin{array}{l}\mathrm{J}^{*} \\
\mathrm{~J} 40^{*}-\mathrm{J} 47^{*}\end{array}$ & $\begin{array}{l}\text { All } \\
\geqslant 65\end{array}$ & $\begin{array}{l}5878 \\
1441\end{array}$ & $\begin{array}{l}0.11 \%(0.04-0.20)^{16} \\
0.25 \%(0.06-0.46)^{16}\end{array}$ & & \\
\hline Circulatory admissions & $390-459$ & $1^{*}$ & $\begin{array}{l}0-64 \\
\geqslant 65\end{array}$ & $\begin{array}{l}9461 \\
19410\end{array}$ & $\begin{array}{l}0.11 \%(0.04-0.18)^{17} \\
0.05 \%(-0.00 \text { to }+0.10)^{17}\end{array}$ & $0.05 \%(0.02-0.08)^{18}$ & \\
\hline Cardiac admissions & $390-429$ & $100-130$ & $\begin{array}{l}\text { all ages } \\
>65\end{array}$ & $\begin{array}{l}20611 \\
13870\end{array}$ & $0.08 \%(0.03-0.14)^{32}$ & $\begin{array}{l}0.05 \%(0.02-0.08)^{10} \\
0.07 \%(0.04-0.10)^{10}\end{array}$ & \\
\hline IHD admissions & $410-414$ & $|20-| 25$ & $\begin{array}{l}0-64 \\
\geqslant 65\end{array}$ & $\begin{array}{l}4151 \\
6303\end{array}$ & $\begin{array}{l}0.13 \%(0.03-0.25)^{17} \\
0.08 \%(0.01-0.16)^{17}\end{array}$ & $0.08 \%(0.03-0.12)^{10}$ & \\
\hline $\begin{array}{l}\text { Respiratory } \\
\text { admissions }\end{array}$ & $460-519$ & $J^{*}$ & All & 27345 & $0.08 \%(0.03-0.16)^{17}$ & & $\begin{array}{l}0.08 \%(0.05 \text { to } 0.11) \\
(\mathrm{WHO})^{28} 29\end{array}$ \\
\hline $\begin{array}{l}\text { COPD + asthma } \\
\text { admissions }\end{array}$ & $490-496$ & $J 40-J 47$ & $\begin{array}{l}\geqslant 65 \\
\geqslant 65\end{array}$ & $\begin{array}{l}12045 \\
4931\end{array}$ & $\begin{array}{l}0.04 \%(-0.03 \text { to }+0.12)^{32} \\
0.04 \%(-0.03 \text { to } 0.12)^{18} \\
0.03(-0.08 \text { to }+0.15)^{18}\end{array}$ & $\begin{array}{l}0.1 \%(0.04-0.15)^{18} \\
0.1 \%(0.04-0.15)^{18}\end{array}$ & \\
\hline $\begin{array}{l}\text { Lower respiratory } \\
\text { infection admissions }\end{array}$ & $466,480-486$ & J12-J22 & $\geqslant 65$ & 5542 & $0.13 \%(0.02-0.25)^{17}$ & & \\
\hline Asthma admissions & 493 & $J 45-J 46$ & $\begin{array}{l}0-14 \\
15-64\end{array}$ & $\begin{array}{l}2251 \\
1955\end{array}$ & $\begin{array}{l}0.06 \%(-0.08 \text { to }+0.2)^{18} \\
0.14 \%(-0.01 \text { to }+0.3)^{18}\end{array}$ & $\begin{array}{l}0.12 \%(0.02-0.23)^{18} \\
0.11 \%(0.03-0.18)^{18}\end{array}$ & \\
\hline $\begin{array}{l}\text { Asthma attendances } \\
\text { at } A \& E\end{array}$ & self reported & & $\begin{array}{l}0-14 \\
15-64\end{array}$ & $\begin{array}{l}\text { Not available } \\
\text { Not available }\end{array}$ & $\begin{array}{l}0.30 \%(0.09-0.50) \\
\text { cumulative }^{19} \\
0.24 \%(0.07-0.42) \\
\text { cumulative }^{19}\end{array}$ & & \\
\hline
\end{tabular}

APHEA, short term effects of air pollution on health: European approach. NMMAPS, national mortality and morbidity air pollution study. WHO, World Health Organisation. COPD, chronic obstructive pulmonary disease. IHD, ischaemic heart disease. A\&E, accident and emergency department. 


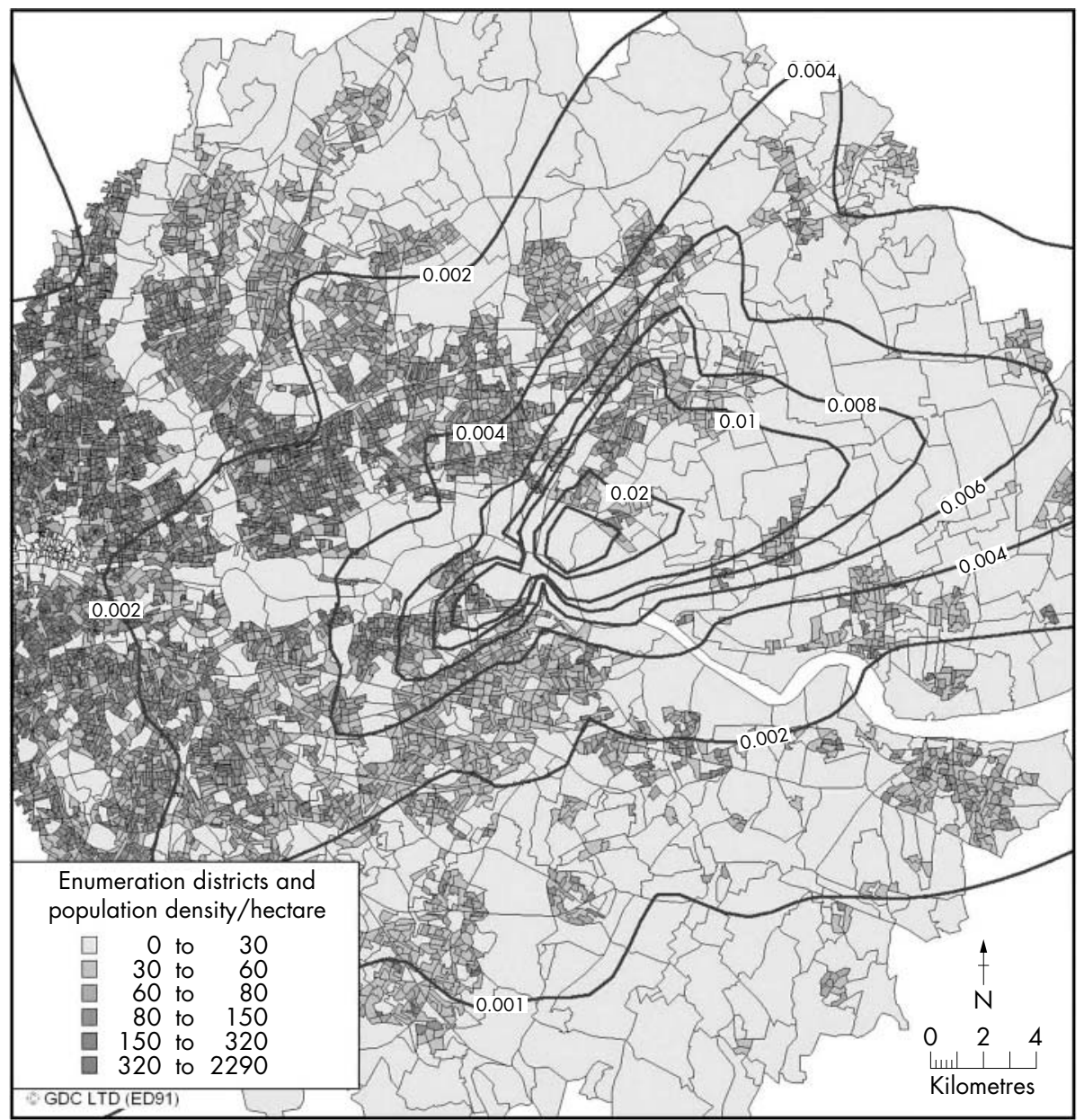

Figure 1 Additional mean annual $\mathrm{PM}_{10}$ levels from the proposed incinerator (20 km radius).

Using the GIS it was possible to see, at a glance, the population density variations across the study area and in conjunction with the distribution of pollutant concentrations. It was a straightforward exercise to add new data into the GIS and run the model again, for a larger area for example. Similarly, the model could be run with different pollutant concentration fields.

The results from the GIS were then exported into MSExcel so that further calculations could be made.

Aggregated data on current regional rates of mortality and hospital admissions for several causes from the Office for National Statistics (ONS) and Hospital Episode Statistics databases respectively were obtained from the Compendium of Clinical and Health Indicators 2002/Clinical and Health Outcomes Knowledge Base and the London Health
Observatory. We used a three year average to reduce the effects of random variation.

The GIS is linked to a spreadsheet containing the effect estimates and the background rates for the various health outcomes.

A number of uncertainties exist in the information underlying this assessment. We therefore included three types of sensitivity analyses. Precise effect estimates from relevant, well conducted primary studies and from metaanalyses are of the same order of magnitude but vary (table 2), so the analyses were repeated using a number of coefficients. The analyses were repeated using a $15 \mathrm{~km}$ radius for impacts, to see the effect of changing the geographically determined population for which health impacts are assessed. Thirdly, for a "worst case scenario" approach, we

Table 3 Acute effects on premature deaths of extra $\mathrm{PM}_{10}$ within $20 \mathrm{~km}$ of the proposed facility

\begin{tabular}{|c|c|c|c|c|c|}
\hline \multirow[b]{2}{*}{ Cause of death } & \multirow[b]{2}{*}{ Age } & \multirow[b]{2}{*}{ Source of exposure-effect estimate } & \multicolumn{3}{|c|}{ Deaths brought forward by operation of facility per annum } \\
\hline & & & $\begin{array}{l}\text { Number } \\
\text { per year }\end{array}$ & $\begin{array}{l}\text { Number in } 30 \\
\text { years }\end{array}$ & As $\%$ of baseline \\
\hline Total non-traumatic & All & $\begin{array}{l}\text { London } \\
\text { Combined APHEA and NMMAPS, } 2002 \\
\text { APHEA } \\
\text { COMEAP } \\
\text { APHEA (distributed lag) }\end{array}$ & $\begin{array}{l}0.018 \\
0.030 \\
0.036 \\
0.045 \\
0.097\end{array}$ & $\begin{array}{l}0.55 \\
0.91 \\
1.09 \\
1.38 \\
2.91\end{array}$ & $\begin{array}{l}0.00006 \\
0.0001 \\
0.0001 \\
0.0002 \\
0.0003\end{array}$ \\
\hline $\begin{array}{l}\text { Respiratory } \\
\text { COPD + asthma }\end{array}$ & $\begin{array}{l}\text { All } \\
\geqslant 65\end{array}$ & $\begin{array}{l}\text { London } \\
\text { London }\end{array}$ & $\begin{array}{l}0.013 \\
0.0078\end{array}$ & $\begin{array}{l}0.39 \\
0.23\end{array}$ & $\begin{array}{l}0.0002 \\
0.0005\end{array}$ \\
\hline
\end{tabular}

APHEA, short term effects of air pollution on health: European approach. NMMAPS, national mortality and morbidity air pollution study. COMEAP, Committee on Medical Effects of Air Pollution. COPD, chronic obstructive pulmonary disease. 
Table 4 Acute effects on admissions and consultations of extra $\mathrm{PM}_{10}$ within $20 \mathrm{~km}$ of the proposed facility

\begin{tabular}{llllll}
\hline & & & \multicolumn{2}{l}{ Number of extra or earlier admissions and consultations per annum } \\
\cline { 5 - 6 } Emergency hospital admissions & Age & Source & Number per year & Number in $\mathbf{3 0}$ years & As \% of baseline \\
\hline Respiratory & All & London & 0.044 & 1.32 & 0.0002 \\
& & COMEAP & 0.044 & 1.32 & 0.0002 \\
& $\geqslant 65$ & London & 0.010 & 0.31 & 0.00009 \\
Asthma & & APHEA & 0.026 & 0.78 & 0.0002 \\
COPD + asthma & $0-14$ & London & 0.003 & 0.08 & 0.0001 \\
LRTI & $15-64$ & London & 0.006 & 0.17 & 0.0003 \\
Circulatory & $\geqslant 65$ & London & 0.003 & 0.10 & 0.0002 \\
& & APHEA & 0.011 & 0.32 & 0.0003 \\
Cardiac & 265 & London & 0.016 & 0.47 & 0.0001 \\
IHD & All & APHEA & 0.029 & 0.87 & 0.0003 \\
& $0-64$ & London & 0.029 & 0.87 & 0.0001 \\
& $\geqslant 65$ & London & 0.021 & 0.63 & 0.0001 \\
& All & APHEA & 0.021 & 0.63 & 0.0002 \\
& $\geqslant 65$ & APHEA & 0.021 & 0.63 & 0.0002 \\
& $0-64$ & London & 0.011 & 0.33 & 0.0002 \\
\hline
\end{tabular}

COMEAP, Committee on Medical Effects of Air Pollution. APHEA, short term effects of air pollution on health: European approach. COPD, chronic obstructive pulmonary disease. LRTI, lower respiratory tract infection. IHD, ischaemic heart disease.

used the event rates from the local government area within the $20 \mathrm{~km}$ circle that had the highest background rates of deaths and hospital admissions.

\section{RESULTS}

The modelled changes in annual mean concentrations of $\mathrm{PM}_{10}$ were small, being $0.08 \mu \mathrm{g} / \mathrm{m}^{3}$ at the most affected location (fig 1; a colour version of the figure is available on line at http://www.jech.com/supplemental). The average additional exposure over the area within $20 \mathrm{~km}$ would be $0.002 \mu \mathrm{g} / \mathrm{m}^{3}$. Even at the most affected location, concentration increases of this magnitude would be impossible to detect through the use of monitoring instruments, given current background concentrations of about $25 \mu \mathrm{g} / \mathrm{m}^{3}$ and the precision of current instruments $\left( \pm 2 \mu \mathrm{g} / \mathrm{m}^{3}\right)$.

At baseline, the 3689826 population living within $20 \mathrm{~km}$ of the proposed plant experienced an average of 29984 nontraumatic deaths, 28541 cardiovascular and 27345 respiratory admissions per year. Table 3 shows the estimated number of deaths brought forward by operation of the facility.

Using a $20 \mathrm{~km}$ radius, the additional $\mathrm{PM}_{10}$ emitted from the proposed plant was estimated to bring forward about 0.03 deaths per year-that is, 0.9 earlier death, including 0.39 earlier respiratory death, every 30 years, corresponding to $0.0001 \%$ of all deaths.

Table 4 shows extra or earlier hospital admissions. There would be about 1.3 extra or earlier emergency respiratory admissions, and 0.9 extra or earlier emergency cardiovascular admissions in 30 years, $<0.0002 \%$ of all respiratory and $0.0001 \%$ of all circulatory admissions.

Over a 30 year period, there would be 0.08 extra or earlier hospital admission among children aged less than 15 years and 0.17 in adults aged 16 to 64 for asthma. Visits to accident and emergency departments for asthma could not be calculated, as neither baseline numbers nor rates were available.

\section{Long term effects}

There is less evidence for the long term effects of particulate exposure. Three American ${ }^{33-35}$ and one Dutch ${ }^{36}$ cohort studies have found associations with increased mortality. Re-analysis adjusting for a wide range of sociodemographic and other potential confounder confirmed a probable effect, although with smaller effect estimates. ${ }^{37}$

The effect is probably causal but the magnitude of effect has not been measured in England. The English Committee on the Medical Effects of Air Pollution (COMEAP), stated in $2001^{38}$ that the most probable effect estimate was the lower limit reported by the Health Effects Institute reanalysis $-0.1 \%$ per $1 \mu \mathrm{g} / \mathrm{m}^{3} \mathrm{PM}_{2.5}{ }^{37}$

The long term effects of 30 year exposure to the estimated additional $\mathrm{PM}_{10}$ over the area within $20 \mathrm{~km}$ of the proposed plant would cause between an extra 1.8 deaths in 30 years (using as our lower limit the COMEAP "most likely" effect estimate of $0.1 \%$ per $1 \mu \mathrm{g} / \mathrm{m}^{3} \mathrm{PM}_{2.5}$ and applying this effect estimate to the $\mathrm{PM}_{10}$ levels) and 7.8 deaths in 30 years (using the weighted average estimate from the WHO three country study $\left.{ }^{39}\right)$.

\section{Sensitivity analyses}

Table 5 summarises the results of sensitivity analyses for which the effect estimate, baseline mortality rate, or area affected were varied.

The most important effect on health is the increase in nontraumatic deaths. Different exposure effect estimates gave

Table 5 Examples of sensitivity analyses for increases in annual health outcomes

\begin{tabular}{llllll}
\hline Health outcome & Age group & Base Estimate & $\begin{array}{l}\text { Higher exposure response } \\
(\mathbf{2 0} \mathbf{~ k m})\end{array}$ & $\begin{array}{l}\text { Higher baseline rate } \\
(\mathbf{2 0} \mathbf{~ k m})\end{array}$ & $\begin{array}{l}\text { Smaller population } \\
(\mathbf{1 5} \mathbf{~ k m})\end{array}$ \\
\hline Total non-traumatic deaths & All & 0.030 & 0.045 (based on $0.074 \%)$ & 0.042 \\
COPD+ asthma deaths & $\geqslant 65$ & 0.0078 & 0.014 (based on $0.46 \%)$ & - & 0.024 \\
Respiratory admissions & All & 0.044 & - & - & 0.0063 \\
Cardiac admissions & $\geqslant 65$ & 0.021 & 0.030 (based on $0.1 \%)$ & - & 0.035 \\
Asthma admissions & $0-14$ & 0.0027 & 0.0055 (based on $0.12 \%)$ & - & 0.017 \\
Asthma admissions & $15-64$ & 0.0055 & 0.0070 (based on $0.18 \%)$ & - & 0.0022 \\
\hline
\end{tabular}


the range for the estimated acute impact on mortality as 0.55-2.91 earlier deaths every 30 years.

The primary calculation used the region's average death rate, but there is pronounced geographical variation in this rate. Using the highest all cause death rate experienced in a borough within $20 \mathrm{~km}$ of the proposed plant as a worse case scenario had a similar effect to increasing the exposure effect estimate: it increased the estimate of the number of deaths brought forward to 1.26 in 30 years.

Considering the population living within $15 \mathrm{~km}$ (2 214 151) rather than $20 \mathrm{~km}$ of the proposed plant reduced the number of deaths brought forward by the additional $\mathrm{PM}_{10}$ emitted over a 30 year period from 0.91 to 0.72 .

\section{DISCUSSION}

Exposure response coefficients from American and European epidemiological studies apply best to those populations and pollution types for which the studies were done. These have tended to be urban populations where pollution is influenced primarily by road traffic pollution. The influence of industrial pollution in urban areas is much less than it was several decades ago. For particles, there is be more reason to consider the source of pollution, as particulate matter is usually a composite of many chemicals, although the consistency of association between outcomes and mass of $\mathrm{PM}_{10}$ from studies in different parts of the world is striking.

Some factors that may increase the uncertainty are:

- The temporal nature of the pollution. Industrial plumes expose a downwind population to intermittent, short periods of higher concentrations. Road traffic pollution in urban areas is more uniform, with occasional episodes of increased concentrations caused by unfavourable weather conditions.

- The socioeconomic circumstances of the two population groups. In our example, the exposed population is mainly urban and reflects well the populations used in epidemiological studies of pollution mainly originating from transport.

The English Department of Health's expert committee on health effects of air pollution (COMEAP) has confirmed that it is appropriate to use the results of time-series studies from transport pollution for estimating effects of industrial pollution but has reported on the additional uncertainties. ${ }^{40}$ In line with their recommendations, we have been explicit about assumptions made.

The more widely practised methods of quantifying health outcomes from exposure to air pollutants in environmental assessment have usually entailed a source-pathway-receptor approach, in which each various exposure route is treated as a series of compartments thorough which the pollutants are transferred. A large number of pollutants are amenable to this treatment and their effects on humans are calculated by reference to toxicological data. This approach is popular in North America, where the concept of risk assessment is embedded in regulatory practice. ${ }^{41}{ }^{42}$ The approach we outline

\section{What this paper adds}

- Combining a GIS system, dispersion modelling, and a spreadsheet model to quantify potential health impacts of new or existing sources of pollution is feasible.

- Using such an approach, sensitivity analyses are easily performed, to examine the effects of changing the underlying assumptions. here is fundamentally different, not least with respect to the origin of the data relating to harm. The North American approaches to the evaluation of health risk rely on the use of large toxicology databases for an array of chemicals. Information on individual chemicals is typically based on animal and occupational exposure data. For carcinogens, a non-threshold approach is adopted and so a theoretical risk extends to all non-zero exposures, however small. For noncarcinogens, a reference dose is used, which signifies the point at which harm is assumed to occur. Often, the technique is applied to defined human receptors that are taken to represent specific exposure scenarios, such as a farmer or child. Significant parts of the modelling elements of the risk assessment approach are concerned with the estimation of exposure, either to inhalation or ingestion, perhaps through the food chain.

In contrast, the approach we describe here is limited to a small number of pollutants, but the basis of the estimation of harm is the reported effect from epidemiological studies on the wider human population. It is also not a measure of the risk of harm occurring, but rather an attempt to quantify an outcome assumed, from an assessment of causality from a systematic literature review, to occur. We assume that the exposure of the affected population is well represented by the dispersion model and we include only inhalation of airborne pollutants.

The California Environmental Protection Agency approach, and its HARP (hotspots analysis reporting program) software, can be linked to a GIS but assumes a threshold relation for non-carcinogenic air pollution effects. ${ }^{41}$ The impacts of a proposed development are therefore based on calculating the health impacts of air pollution with and without the proposal, the impacts of the development being the difference between the two. Because of the assumption of a threshold, annual averages cannot be used but each day's particulate levels (or hourly levels for some pollutants) are required to be computed separately and the effects summed.

Our computer model uses a similar theoretical approach to quantifying health impacts as Health Canada's revised risk determination framework. ${ }^{43}$ We have produced a tool to estimate these impacts.

The mathematical model developed by Biddulph and colleagues ${ }^{14} 44$ uses more detailed population dynamics than our model but in the absence of more detailed age specific exposure-effect estimates, we decided not to use population data broken down into more than the three age bands. If the population in the potentially affected areas within each of the adult age groups were older than average, a higher baseline number of events and therefore greater impact would have been found by using narrower age specific baseline event rates. Their model also incorporates baseline health status and models transition between these for a "no intervention" and a "proposed project" scenario, the health impact of the proposal being the difference between these. However, such detailed population and health status data are seldom available to those conducting environmental health impact assessments, nor have the time series studies on which the exposure-effect estimates are based used such data. Their model also does not seem to incorporate geographical information.

\section{Policy implications}

Where environmental effects are of concern because of their potential impacts on health, these should be identified and, where possible, quantified. 
Like Health Canada's approach to estimating health benefits, ${ }^{45}$ but unlike the tools mentioned above, our approach uses the change model ${ }^{46}$ rather than a burden of disease approach. ${ }^{46}{ }^{47}$ This has the advantage of ignoring factors that do not change, thus simplifying the calculations. This is particularly important for aspects such as baseline air pollution levels, which are generally available only at a few specified locations. A model that requires calculation of the effects both of baseline pollution exposure and of exposure to the "baseline plus effects of proposal" would therefore require spatial modelling of pollutant levels at a small area resolution if modelled exposure to pollution from a proposed development is to be estimated accurately.

This approach is also applicable to other impacts, provided the change in "exposure", the magnitude of effects of a unit change, and the baseline rates are known, and to other sources, if changes in exposure can be modelled. It could also be used to model differential effects on susceptible populations if effect estimates for different subgroups became available, together with the relevant population data. This model does already allow for the tendency for more deprived populations to be exposed to greater concentrations of pollutants because of its fine geographical resolution in modelling air pollution and its consequent health impacts. The additional refinement of using area specific baseline mortality and morbidity rates would add to the assessment of equity of effects.

It is possible to quantify the impact on some health outcomes of exposure to some additional levels of pollution, caused by a new point source. Using a GIS in this way can result in a more precise estimate, as the modelled exposure for each small area can be related to the resident population of that area, rather than applying a uniform average or maximum exposure to all. Our approach might be particularly suitable for the case of air quality changes introduced by a linear pollutant source, such as a road, or changes across a road network on the scale of a city, provided that such air quality changes can be captured within a GIS and matched with a population database at the appropriate spatial resolution.

The main advantage of this computer model approach is the ease with which the input data can be varied to reflect changing knowledge, such as more recent effect estimates $^{48}{ }^{49}$; other effect estimates to enable comparisons with those used elsewhere'; other underlying assumptions (for example, normal operating conditions or worse case scenarios); or the level of uncertainty in the data (and therefore the need to conduct sensitivity analyses). When more than one pollutant is considered, effect estimates obtained from analyses using two-pollutant models can be substituted. ${ }^{16}$

A similar model was used in the past to ascertain whether calculations using annual changes in sulphur dioxide differed from those using monthly changes. ${ }^{50}$ No significant difference in conclusions were found, so that empirical study confirms our theoretical basis for using annual changes for a pollutant with no threshold of effect.

This method can also show the effects of varying the geographical parameters within which exposure is defined. Eighty per cent of the potential health effects seen when a $20 \mathrm{~km}$ radius was used occur within $15 \mathrm{~km}$ of the proposed plant, although only $60 \%$ of the larger population live within this smaller area. Extending the area further would be unlikely to have more than a minimal effect.

Simple calculations of health effects of modelled changes in air pollution have been undertaken in the past, examining the benefits of improvements in air quality ${ }^{13}$ or potential hazards from increased pollution from a development. ${ }^{51}$ Our computerised approach permits more sophisticated modelling. Whereas those studies assumed that all the residents of the selected area would be exposed to the same estimated concentrations, the basis of our method is to model air pollution concentrations at a fine geographical resolution and use GIS to ascertain the effects of the modelled concentration of the pollutant for each enumeration district on the population living within that small area.

Additionally, our computer model enables different background rates to be applied to each area for more precise estimates. In this case, we used localised population and modelled air pollution data but did not incorporate specific background mortality or morbidity rates for each local authority area as the numbers were so small that using the regional average and the highest local authority rate within the affected area were deemed sufficient analysis.

The estimates are a useful order of magnitude guide to some health impacts. Application of the method in this case was able to show that the magnitude of quantifiable health effects that might result from the increased exposure to $\mathrm{PM}_{10}$ is small-about 0.03 deaths each year in a population of 3500 000, with 0.04 extra hospital admissions for respiratory disease.

In comparison with the more deterministic modelling approaches to calculating health impact, our approach is restricted to those pollutants for which we have strong evidence of causality through epidemiological studies. However, these tend to be the pollutants associated with combustion processes and so are those of primary interest. In addition, particulate matter is not a pollutant that is easily treated by reference to toxicological data derived from occupational exposure or animal studies and its effects on the human population could be missed by such an approach.

This is a useful technique but is only a part of identifying potential health impacts. A similar model can be used to quantify any causal impact if the exposure can be modelled and the baseline event rate, susceptible population, and the magnitude of a linear exposure-effect relation are known. ${ }^{13}$ It can also be used to compare potential health impacts from different proposals as part of options appraisal or within an economic assessment. However, it cannot be used to compare the magnitude of health impacts from different proposals or caused by different aspects of a proposal (for example, from transport of waste, effects on visual amenity, noise) unless all the elements to be compared are quantifiable. ${ }^{13}$

The extent to which deaths are brought forward is debated..$^{52-55}$ The long lasting effects of long term exposure to lower levels of pollution are generally held to be considerably larger than the acute effects. ${ }^{56}$ However, the effects of long term exposure to pollution are still an order of magnitude less than the premature deaths caused by smoking, where each smoker whose death is caused by tobacco loses an average of 10 years of life. ${ }^{57}$

Some care must be taken in presenting these results to emphasise the uncertainties in the numbers and the limitations of the method. Nevertheless, for decision makers who might be unclear on the scale of possible impacts, the methodology is a useful tool. For the public, context is crucial: for them even one premature death might be seen as an unnecessary burden from a new source appearing in their community.

\section{ACKNOWLEDGMENTS}

We thank Kate Murray for her GIS work for this project; Dr Mike Joffe for help with developing the model and commenting on earlier drafts of this paper; and Dr Bob Humphries for helpful comments.

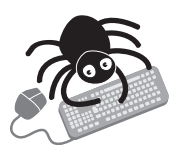

A colour version of the figure is available on line at http://www.jech.com/supplemental. 


\section{Authors' affiliations}

J Mindell, Imperial College London, UK

R Barrowcliffe, Environmental Resources Management, London, UK

Funding/competing interests: $J M$ and RB were funded by the company that was proposing to build the waste facility.

\section{REFERENCES}

1 Interorganizational Committee on Guidelines and Principles. Guidelines and principles for social impact assessment Impact Assessment 1994:12:107-52.

2 Joffe M, Sutcliffe J. Developing policies for a healthy environment. Health Prom Int 1997; 12:169-73.

3 Fehr R. Environmental health impact assessment: evaluation of a ten-step model. Epidemiology 1999;10:618-25

4 Chapman R. A guide to town planning for the health service in London. London: London Health Observatory, 2001.

5 Birley MH. Health impact assessment of development projects. In: Wood C Wynberg R, Raimondo J, eds. Impact assessments: involving people in the management of change towards a sustainable future. Proceedings of the 15th annual IAIA meeting, 26-30 Jun 1995, Durban, South Africa: 69-81.

6 Birley M, Boland A, Davies L, et al. Health and environmental impact assessment. An integrated approach. London: Earthscan, 1998.

7 Walter U, Machtolf $M$. Status quo analysis of the topic health as far as the practice of environmental impact assessment in North Rhine-Westphalia is concerned. Oral presentation at the scientific meeting on health impact assessment of transportationthe regional perspective, 17-18 May 1999 Bielefeld, Germany.

8 National Institute for Health and Clinical Excellence. HIA gateway. http:// www.publichealth.nice.org.uk/page.aspx?o = HIAGateway (accessed 28 Jun 2005)

9 Department of Health Committee on the Medical Effects of Air Pollutants. Quantification of the effects of air pollution on health in the United Kingdom. London: HMSO, 1998

10 Le Tertre A, Medina S, Samoli E, et al. Short-term effects of particulate air pollution on cardiovascular diseases in eight European cities. J Epidemiol Community Health 2002;56:773-9.

11 Zanobetti A, Schwartz J, Samoli E, et al. The temporal pattern of mortality responses to air pollution: a multicity assessment of mortality displacement. Epidemiology 2002;13:87-93.

12 Samet JM, Dominici F, McDermott A, et al. New problems for an old design: time series analyses of air pollution and health. Epidemiology 2003;14:11-12.

13 Mindell J, Joffe M. Predicted health impacts of urban air quality management. $J$ Epidemiol Community Health 2004;58:103-13.

14 McCarthy M, Biddulph J, Utley M, et al. A health impact assessment model for environmental changes attributable to development projects. J Epidemiol Community Health 2002;58:611-16.

15 Mindell JS. Quantification of the health impacts of air pollution reduction in Kensington and Chelsea and Westminster. (PhD thesis). London: Imperial College of Science, Technology and Medicine, University of London, 2002.

16 Bremner SA, Anderson HR, Atkinson R, et al. Short term associations between outdoor air pollution and mortality in London 1992-4. Occup Environ Med 1999;56:237-44.

17 Atkinson RW, Bremner SA, Anderson HR, et al. Short-term associations between emergency hospital admissions for respiratory and cardiovascular disease and outdoor air pollution in London. Arch Environ Health 1999:54:398-411.

18 Atkinson RW, Anderson HR, Sunyer J, et al. Acute effects of particulate air pollution on respiratory admissions: results from APHEA 2 project. Am J Respir Crit Care Med 2001;164:1860-6.

19 Atkinson RW, Anderson HR, Strachan DP, et al. Short-term associations between outdoor air pollution and visits to accident and emergency departments in London for respiratory complaints. Eur Respir 1999; 13:257-65

20 Pope CAI. Particulate matter-mortality exposure-response relations and threshold. Am J Epidemiol 2000;152:407-12.

21 World Health Organisation. Guidelines for air quality. Geneva: WHO, 2000

22 World Health Organisation. Health aspects of air pollution with particulate matter, ozone and nitrogen dioxide. Copenhagen: WHO, 2003

23 Cambridge Environmental Research Consultants. http://www.cerc.co.uk (accessed 28 Jun 2005)

24 McHugh CA, Carruthers DJ, Edmunds HA. DMS and ADMS urban. Int J Environ Pollut 1997;8:437-40.

25 World Health Organisation. Manual of the international statistical classification of diseases, injuries, and causes of death. London: HMSO, 1977.

26 World Health Organisation. International statistical classification of disease and related health problems. Geneva: WHO, 1992

27 Katsouyanni K, Touloumi G, Samoli E, et al. Confounding and effect modification in the short-term effects of ambient particles on total mortality: results from 29 European cities within the APHEA2 project. Epidemiology $2001 ; 12: 521-31$

28 World Health Organisation Regional Office for Europe. Air quality guidelines for Europe. 2nd ed. Copenhagen: WHO, Regional Office for Europe, 2000.
29 World Health Organisation Regional Office for Europe. Particulate matter. In: Air quality guidelines for Europe. Copenhagen: WHO, Regional Office for Europe, 2000.

30 Stieb DM, Judek S, Burnett RT. Meta-analysis of time-series studies of air pollution and mortality: effects of gases and particles and the influence of cause of death, age, and season. J Air Waste Manag Assoc 2002;52:470-84

31 Anderson HR, Atkinson RW, Peacock JL, et al. Publication bias in studies of ambient particulate pollution and daily mortality. Vancouver, ISEA/ISEE. Linking exposures and health: innovations and interactions, 12th Conference of the international society of exposure analysis and 14 th conference of the international society for environmental epidemiology, 2002.

32 Wong CM, Atkinson RW, Anderson HR, et al. A tale of two cities: effects of air pollution on hospital admissions in Hong Kong and London compared. Environ Health Perspec 2002;1 10:67-77.

33 Dockery DW, Pope CAI, Xu X, et al. An association between air pollution and mortality in six US cities. N Engl J Med 1993;329:1753-9.

34 Abbey DE, Nishino N, McDonnell WF, et al. Long-term inhalable particles and other air pollutants related to mortality in nonsmokers. Am J Respir Crit Care Med 1999; 159:373-82

35 Pope CA III, Burnett RT, Thun MJ, et al. Lung cancer, cardiopulmonary mortality, and long-term exposure to fine particulate air pollution. JAMA 2002;287: 1132-41.

36 Hoek G, Brunekreef B, Goldbohm S, et al. Association between mortality and indicators of traffic-related air pollution in the Netherlands: a cohort study. Lancet 2002;360:1203-9.

37 Krewski D, Burnett RT, Goldberg MS, et al. Reanalysis of the Harvard six cities study and the American Cancer Society study of particulate air pollution and mortality. Cambridge, MA: Health Effects Institute, 2000.

38 Department of Health Committee on the Medical Effects of Air Pollutants. Statement and report on long-term effects of particles on mortality. London: Department of Health, 2001. http://www.advisorybodies.doh.gov.uk/ comeap/statementsreports/longtermeffects.pdf (accessed 26 Jun 2005)

39 Künzli N, Kaiser R, Medina S, et al. Public-health impact of outdoor and traffic-related air pollution: a European assessment. Lancet 2000;356:795-800

40 Department of Health Committee on the Medical Effects of Air Pollutants. Statement on the applicability of time-series coefficients to areas affected by emissions of air pollutants from industrial sources. London: Department of Health, 2000. http://www.advisorybodies.doh.gov.uk/comeap/ statementsreports/areaemissions.htm (accessed 4 Dec 2005).

41 Hickox WH, Denton JE. The air toxics hot spots program guidance manual for preparation of health risk assessments. Los Angles: Office of Environment Health Hazards Assessment, California Environmental Protection Agency 2003. http://www.oehha.ca.gov/air/hot_spots/pdf/HRAfinalnoapp.pdf (accessed 13 Oct 2005)

42 US EPA (Environmental Protection Agency). Human health risk assessment protocol for hazardous waste combustion facilities. http://www.epa.gov/ epaoswer/hazwaste/combust/risk.htm (accessed 20 Dec 2004)

43 Health Canada. Health and Air Quality Risk Assessment 2003. http:// www.hc-sc.gc.ca/hecs-sesc/air_quality/risk.htm (accessed 30 Nov 2004).

44 Biddulph J, Ferguson J, Gallivan S, et al. Environmental health impact assessment: developing a quantitative model. 3rd UK HIA conference, Liverpool, 17-18 Oct, 2000

45 Health Canada. Estimating health benefits. 2003. http://www.hc-sc.gc.ca/ hecs-sesc/air quality/health effects.htm \#8 (accessed 30 Nov 2004).

46 Joffe M, Mindell J. A framework for the evidence base to support health impact assessment. J Epidemiol Community Health 2002;56:132-8.

47 Ezzati M, Lopez AD, Rodgers $A$, et al. Selected major risk factors and global and regional burden of disease. Lancet 2002;360:1347-60.

48 Dominici $F$, McDermott A, Zeger SL, et al. On the use of generalized additive models in time-series studies of air pollution and health. Am J Epidemiol 2002; 156:193-203

49 Stieb DM, Judek S, Burnett RT. Meta-analysis of time-series studies of air pollution and mortality: update in relation to the use of generalized additive models. J Air Waste Manag Assoc 2003;53:258-61.

50 Basham J. Application of COMEAP dose-response coefficients within a regulatory health impact assessment methodology. J Public Health Med 2001;23:212-18.

51 Jewell T. Alconbury health impact assessment report. Cambridge: Cambridgeshire Health Authority, 2000

52 Ostro BD, Chestnut LG. Inappropriate use of daily mortality analyses to estimate longer-term mortality effects of air pollution. Int J Epidemiol 1999:28:990-1.

53 McMichael AJ, Anderson HR, Brunekreef B, et al. Inappropriate use of daily mortality analyses to estimate longer-term mortality effects of air pollution. Int J Epidemiol 1999;28:991-2.

54 Zeger SL, Dominici F, Samet J. Harvesting-resistant estimates of air pollution effects on mortality. Epidemiology 1999;10:171-5.

55 Schwartz J. Harvesting and long term exposure effects in the relation between air pollution and mortality. Am J Epidemiol 2000;151:440-8.

56 Dominici F, McDermott A, Zeger SL, et al. Response to Dr Smith: Timescaledependent mortality effects of air pollution. Am J Epidemiol 2003; 157:1071-3

57 Doll R, Peto R, Boreham J, et al. Mortality in relation to smoking: 50 years observations on male British doctors. BMJ 2004;328:1519-20. 